\title{
PELATIHAN MANAJEMEN KESELAMATAN KERJA DAN PENATALAKSANAAN PERTOLONGAN PERTAMA PADA KECELAKAAN SERTA ANTISIPASI CEDERA BAGI PELATIH CABANG OLAHRAGA SOFT TENNIS
}

\author{
Kamal Firdaus ${ }^{1}$, Emral $^{2}$ \\ ${ }^{1}$ Jurusan Pendidikan Olahraga, Fakultas Ilmu Keolahragaan, Universitas Negeri Padang \\ Email: kamalfidaus@ fik.unp.ac.id ${ }^{1}$, emral@ fik.unp.ac.id ${ }^{2}$
}

\begin{abstract}
The problem of Coaching Clinic for Field Tennis Branch Trainers in West Sumatra Province was encountered in an ineffective training process, limited trainer ability in the training process, lack of skills and understanding, and minimal facilities and infrastructure. In a sense, the trainer does not have preparation in training, so that the training process is carried out less according to the actual situation. Certainly, this makes it difficult to achieve an athlete's achievement. For this reason, a solution is needed through the Coaching Clinic Activities for Field Branch Sports Field Trainers in West Su matra Province.

Problems encountered in the field: The trainer has not been able to understand and be able to apply the concept of train ing periodization, for this reason, it is necessary to conduct a coaching pattern about the formation of the exercise periodization concept, the trainer has not been able and skilled to develop elements of the physical condition of the Tennis Field athletes. Lack of understanding and knowledge of trainers about management and the training methodology of Field Tennis, so it needs to be equipped with the establishment of the fundamentals of management training following the sport that will be developed. Lack of values and attitudes towards the development of Tennis Field sports so far, it is necessary to give tips in management in the form of entrepreneurial activities and other patterns that are not binding.

In this activity, the strategic target audience was the trainers of the Tennis Field Sports Branch in West Sumatra Province, as many as 25 people were recru ited in collaboration with the Executive Board of West Sumatra Province. The Coaching Clinic for Trainers in the Field of Sports in the Field in West Sumatra Province was held for 6 months, which took place at the PT.TELKOM West Sumatra Tennis Court. Method of Activity carried out by the Submission of material and demonstrations.
\end{abstract}

Keywords: Concepts of Exercise, Periodization, Great Coach, Soft Tennis, Sports Management

Abstrak

Masalah Coaching Clinic bagi Pelatih Cabang Olahraga Tennis Lapangan di Provinsi Sumatera Barat di temui proses melatih yang kurang efektif, kemampuan pelatih yang terbatas dalam proses melatih, keterampilan dan pemahaman yang kurang, serta sarana dan pras arana yang minim. Dalam artian, pelatih tidak punya persiapan dalam melatih, sehingga akhirnya proses latihanyang dilakukan kurang sesuai dengan keadaan yang sebenarnya.Tentu halini menyulitkan untuk mencapai prestasi atlet. Untuk itu diperlukan solusi pemecahannya melalui Kegiatan Coaching Clinic bagi Pelatih Cabang OlahragaTennisLapangan di Provinsi Su matera Barat.

Masalah yang ditemui dilapangan: Pelatih belum mampu memahami dan mampu mengaplikasi konsep periodisasi latihan, untuk itu perlu, di lakukan pola pembinaan tentang pembentukan konsep periodesasi latihan, Belum mampu dan terampilnya pelatih mengembangkan elemen kondisi fisik atlet Tennis Lapangan. Kurangnya

60 | Pelatihan Manajemen Keselamatan Kerja Dan Penatalaksanaan

Kamal Firdaus ${ }^{1}$, Emral $^{2}$ 
pemahaman dan pengetahuan pelatih tentang manajemen serta metodologi kepelatihan TennisLapangan, sehingga perlu di bekali dengan pemantapan dasar-dasar manajemen ilmu melatih sesuai dengan cabang olahraga yang akan dikembangkan. Kurangnya nilai dan sikap terhadap pembinaan olahraga Tennis Lapangan selama ini, maka perlu diberikan kiat-kiat dalam manajemen dalam bentuk kegiatan kewirausahaan serta pola-pola lain yang tidak mengikat.

Dalam kegiatan ini yang menjadi khalayak sasaran antara yang strategis adalah para pelatih Cabang Olahraga Tennis Lapangan di Provinsi Sumatera Barat sebanyak 25 orang yang direkrut melalui kerjasama dengan PengurusPELTI Provinsi Sumatera Barat. Pelaksanaan kegiatan Coachiing Clinic bagi Pelatih Cabang OlahragaTennisLapangan di Provinsi Sumatera Barat diadakan selama 6 bulan pelaksanaan, yang bertempat di Lapangan Tenis PT.TELKOM Sumatera Barat. Metode Kegiatan di laksanakan dengan Penyampaian materi dan demontrasi.

\section{Kata kunci : Konsep Latihan, Periodesasi, Pelatih Hebat, Soft Tenis, Manajemen Olahraga}

\section{ANALISIS SITUASI}

Olahraga adalah suatu aktifitas yang banyak dilakukan oleh masyarakat, keberadaannya sekarang ini tidak lagi di pandang sebelah mata tetapi sudah menjadi bagian dari kehidupan masyarakat. Sebab olahraga dewasa ini sudah tren di masyarakat baik orangtua, remaja maupun anak-anak. Karena olahraga ini mempunyai makna tidak hanya untuk kesehatan, tetapi lebih dari itu ialah juga sebagai sarana pendidikan bahkan prestasi. Salah satu usaha untuk menciptakan manusia Indonesia seutuhnya adalah pembinaan generasi melalui olahraga. Seiring dengan Undang-undang Republik Indonesia no 3 (Firdaus. 2005:8) tentang sistem keolahragaan menyatakan:

'Keolahragaan nasional bertujuan memelihara dan meningkatkan kesehatan dan kebugaran, prestasi, kualitas manusia,menanamkan nilai moral dan akhlak mulia, sportifitas, disiplin, mempererat dan membina persatuan dan kesatuan bangsa, memperkokoh ketahanan nasional, serta mengangkat harkat, martabat dan kehormatan bangsa."

Berdasarkan kutipan diatas, jelas bahwa olahraga termasuk salah satu tujuan yang akan dicapai dalam usaha pembinaan dan pengembangan olahraga yang merupakan upaya peningkatan kualitas manusia Indonesia seutuhnya. Melalui kegiatan olahraga diharapkan dapat menciptakan suatu penampilan sikap baru dari seluruh bangsa Indonesia dalam mengisi pembangunan dengan mencapai suatu prestasi olahraga yang optimal. Diharapkan agar pembinaan olahraga dapat terus ditingkatkan mutunya secara optimal guna mencapai prestasi.

\section{1 | Pelatihan Manajemen Keselamatan Kerja Dan Penatalaksanaan Kamal Firdaus ${ }^{1}$, Emral $^{2}$}


JURNAL BERKARYA PENGABDIAN PADA MASYATIALASIJ

Volume 1, No.1, 2019

ISSN -

(Print) I

Open Access / http:jba.ppj.unp.acild

Dengan berjalannya waktu perkembangan ilmu pengetahuan serta teknologi dewasa ini yang berlangsung dengan cepat, banyak menyebabkan pergeseran nilai-nilai kehidupan, baik itu nilai sosial, budaya ekonomi, politik bahkan tanpa terkecuali nilai-nilai olahraga itu sendiri. Olahraga yang dahulunya hanya bertujuan sebagai usaha peningkatan kualitas jasmani, telah berkembang menjadi multifungsi, baik untuk kepentingan prestasi olahraga itu sendiri, ekonomi maupun politik (Asnaldi:2005). Bahkan dewasa ini olahraga telah menjadi suatu industry yang jika dikemas sedemikian rupa mampu menjadi suatu komoditi yang mempunyai nilai jual yang cukup tinggi.

Prestasi olahraga adalah sebuah kata yang sangat mudah diucapkan dan merupakan dambaan setiap orang, namun cukup sulit untuk mencapainya. Dalam pencapaian prestasi di bidang olahraga, diperlukan pembinaan yang baik,meliputi pembinaan fisik, teknik, taktik, strategi, dan mental. Pembinaan tersebut haruslah terencana, berjenjang, dan berkelanjutan, agar prestasi yang diharapkan dapat di capai secara maksimal.

Seperti yang tercantum dalam Undang-Undang Republik Indonesia No. 3 Tahun 2005, tentang sistem Keolahragaan Nasional pasal ayat 13 yang menjelaskan bahwa: "Olahraga prestasi adalah olahraga yang membina dan mengembangkan olahraga secara terencana, berjenjang,dan berkelanjutan melalui kompetisi untuk mencapai prestasi dengan dukungan ilmu pengetahuan dan teknologi keolahragaan".

Dari berbagai cabang olahraga yang telah berkembang luas dan pesat ditengah masyarakat seiring dengan kamajuan ilmu pengetahuan dan teknologi, salah satunya adalah Tenis Lapangan. Permainan Tenis Lapangan sendiri mengalami perkembangan prestasi dengan pesat, ini terbukti dengan berkembangnya olahraga ini dimasyarakat dengan cukup baik.

Permainan Tenis Lapangan telah berkembang dan akan terus berkembang sebagai permainan yang cukup digemari oleh masyarakat. Dalam permainan Tenis Lapangan komponen kondisi fisik sangat berperan dalam hal peningkatan prestasi atlet. Elemen kondisi fisik yang sangat berperan dominan adalah kekuatan dan daya tahan. Pada dasarnya kegiatan yang dilakukan oleh insane olahraga selama ini.

62 | Pelatihan Manajemen Keselamatan Kerja Dan Penatalaksanaan

Kamal Firdaus ${ }^{1}$, Emral $^{2}$ 
Dengan demikian, melalui kegiatan Pengabdian kepada masyarakat ini, akan dilakukan semacam pelatihan/penyegaran kepelatihan bagi pelatih Tenis Lapangan di Sumatera Barat, karena daerah ini memiliki potensi yang cukup memadai baik ditinjau dari segi sumber daya manusianya, ketersed iaan sarana dan prasarananya dan sebagainya.

Kekurangan yang terlihat selama ini adalah persoalan pelatih belummampu memahami dan mampu mengaplikasi konsep periodisasilatihan,sehingga iadapat merencanakanpada turnamenmanakahyang hendaknyaatletyangdilatihmampu berprestasisecara optimal. Selain itu parapelatih belum begitumenyadari dan mengembangkanartipentingnyakomponen-komponen kondisifisikdalamolahragaTenis Lapangan, sehingganyaelemen kondisi fisik cenderungdiabaikan.

\section{SOLUSI DAN TARGET}

Berdasarkanpada uraianyang telah dikemukakanpadabagian terdahulubaik dalamanalisisituasimaupundalamtinjauankepustakaan padabagianterdahulu identifikasi dan perumusanmasalah sebagai berikut :

1. Pelatih belum mampu memahami dan mampu mengaplikasikan konsep periodisasi latihan, untuk itu perlu, dilakukan pola pembinaan tentang pembentukan konsep periodesasi latihan.

2. Belummampudanterampilnyapelatihmengembangkanelemenmetodelatihan atlet tenis lapangandenganbaik.

3. Kurangnya pemahaman dan pengetahuan pelatih tentang manajemen serta metodologi kepelatihan tenis lapangan, sehingga perlu dibekali dengan pemantapan dasar-dasar manajemen ilmu melatih sesuai dengan cabang olahraga yang akandikembangk an.

4. Kurangnya nilai dan sikap terhadap pembinaan kondisi fisik berbagai cabang olahraga selama ini, maka perlu diberikan kiat-kiat perencanaan latihan.

\section{METODE PELAKSANAAN}

\section{Tempat dan Waktu.}

Komplek semen padang, jalan raya indarung.

63 | Pelatihan Manajemen Keselamatan Kerja Dan Penatalaksanaan Kamal Firdaus ${ }^{1}$, Emral $^{2}$ 
JURNAL BERKARYA PENGABDIAN PADA MASYASTAZZATJ

Volume 1, No.1, 2019

ISSN -

(Print) I

(Online)

Open Access / http:jba.ppj.unp.acild

KhalayakSasaran.

Dalam kegiatan ini yang menjadi khalayak sasaran antara yang strategis adalah para-para pelatih

Cabang Olahraga Tennis Lapangan di Provinsi Sumatera Barat sebanyak 25 orang yang direkrut melalui kerjasama dengan Pengurus PELTI Provinsi Sumatera Barat.

\section{Metode Pengabdian}

Dalam menyampaikan materi kepada para pesertaakan dipakai beberapa macam metode dan penggunaan media yang relevan antara lain dengan metode ceramah, diskusi, peragaan dan pemberian tugas sesuai dengan topik-topik yang diberikan.

\section{Indikator Kebe rhasilan.}

Kegiatan ini dirancang sebaik mungkin dan dilaksanakan sesuai dengan jadwal secara professional sehingga diharapkan dapat bermanfaat oleh semua pihak antara lain yaitu :

1. Untuk para peserta pelatihan, sehingga mereka memiliki pengetahuan dan keterampilan dalam bidang kepelatihan tenis lapangan.

2. Mereka akan memiliki sejumlah pengetahuan dan keterampilan dalam bidang dasardasar ilmu melatih sehingga dapat diterapkan dalam masing-masing klub.

3. Bermanfaat bagi klub-klub olahraga, karena mereka akan memiliki pembinaan yang mantap sehingga diharapkan akan lahirlah atlet berbakat yang memiliki prestasi baik ditingkat daerah maupun tingkat nasional.

4. Kegiatan ini bermanfaat pula bagi tenaga pelaksana, karena telah mampu memberikan sumbangan IPTEKS dalam rangka meningkat prestasi olahraga.

5. Laporan kegiatan ini akan bermanfaat pula bagi semua pihak untuk menambah bahan bacaan di perpustakaan sehingga dapat menjadi bahana cuan dalam pengembangan dan peningkatan dalam berbagai hal dimasa mendatang.

\section{Metode Evaluasi.}

Evaluasi dalam kegiatan ini akan dilakukan dalam beberapa tahap antara lain: terhadap persiapan, prosesdan hasil yang dicapai. Evaluasi terhadap persipan dilakukan dengan jalan

64 | Pelatihan Manajemen Keselamatan Kerja Dan Penatalaksanaan

Kamal Firdaus ${ }^{1}$, Emral $^{2}$ 


\section{Volume 1, No.1, 2019}

ISSN-

\section{Open Access | http:jba.ppj.unp.acild}

menilai segala bentuk persiapan dan mendiskusikannya dengan para anggota tim pelaksana. Evaluasi terhadap proses dilakukan sambil berjalan dengan mencocokkan rencana kerja dengan realisasi kegiatan dan evaluasi terhadap hasila kandilakukan dengan Tanya jawab serta peragaan dan pemberian tugas.

\section{HASIL DAN PEMBAHASAN}

Kegiatan ini dilakukan setelah penanda tanganan kontrak kerja dengan pihak pemberi dana melalui LPM UNP Padang dan di rencanakan akan dilaksanakan di Lapangan TELKOM Kandatel SUMBAR atau tempat lain yang memadai. Agar kegiatan ini dapat berjalan dengan lancar, efektif dan efisien, maka perlu disusun rencana kerja untuk di pedomani sebagaiberikut:

Tabel1.

Bagan Rencana Kerja dan Jadwal mulai Bulan Pe rtama Sampai dengan Bulanyang Keenam

\begin{tabular}{|c|c|c|c|c|c|c|c|}
\hline No. & Jenis Kegiatan & $\begin{array}{c}\text { Bulan } \\
5\end{array}$ & $\begin{array}{c}\text { Bulan } \\
6\end{array}$ & $\begin{array}{c}\text { Bulan } \\
7\end{array}$ & $\begin{array}{c}\text { Bulan } \\
8\end{array}$ & $\begin{array}{c}\text { Bulan } \\
9\end{array}$ & $\begin{array}{c}\text { Bulan } \\
10\end{array}$ \\
\hline 1 & $\begin{array}{l}\text { Persiapan: } \\
\text { a. PengajuanProposal b. } \\
\text { Perbaikan Proposal } \\
\text { c. Mengurus Izin dan } \\
\quad \text { Koordinasi } \\
\text { d. Menyiapkantempatdan } \\
\text { peserta } \\
\text { e. CheckingTerakhir }\end{array}$ & $X$ & X X & X X & & & \\
\hline 2 & $\begin{array}{l}\text { Pelaksanaan : } \\
\text { a. Pembukaan } \\
\text { b. PenyajianMateri c. } \\
\text { EvaluasiHasil } \\
\text { d. Pem draftlaporan e. } \\
\text { Finalisasi dan } \\
\quad \text { Penyerahan hasil laporan }\end{array}$ & & & & X X & X X & X X \\
\hline
\end{tabular}

65 | Pelatihan Manajemen Keselamatan Kerja Dan Penatalaksanaan Kamal Firdaus ${ }^{1}$, Emral $^{2}$ 


\section{JURNAL BERKARYA PENGABDIAN PADA MASYALIALZAJ}

Volume 1, No.1, 2019

ISSN-

(Print) I

Open Access | http:jba.ppj.unp.acild

\section{KESIMPULAN}

Sebagai mana yang telah dikemukakan dalam uraian terdahulu bahwa berbagai permasalahan-permasalahan yang ditemui di lapangan sehubungan dengan belum adanya optimalisasi peran pelatih dalam peningktan kemampuan fisik dan teknik dari atlet Tenis Lapangan, untuk itulah perlu kiranya dilakukan penyuluhan dan pelatihan kepada khalayak sasaran antara yang strategis.

\section{DAFTAR PUSTAKA}

Firdaus, K. (2011). Evaluasi Program Pembinaan Olahraga Tenis Lapangan di Kota Padang. Media Ilmu Keolahragaan Indonesia, 1(2).

Asnaldi, A. (2008). Pendidikan jas mani. 